\title{
Assisting Trade Adjustment in Korea: Is it a Facilitating Device for FTA Implementation?*
}

\author{
Yoon $\mathrm{HEO}^{* *}$
}

\begin{abstract}
The Korean government has begun to implement the TAA system since May 2007 in order to support small and medium firms whose sales, production and profits have decreased due to the intensified import competition. This paper analyzes the performance of the Korean TAA program based on the experience for the last five years and aims to suggest some relevant policy implications out of it. We find that the newly introduced Korean TAA system failed to accomplish the objectives of the program it had originally planned. It also failed to be an effective means for internal negotiations. All the efforts to retain marginal firms in comparative disadvantage turned out to be a big failure. This poor performance will threaten the system's own existence in the near future. Even if the TAA system continues to exist, it will inevitably be converted into a worker-centered program instead of a firm-oriented industrial policy. Protecting people by protecting their jobs could be a strategy mistake. With the launch of new government of Korea in 2013, curtailing or abolishing the financial assistance program for marginal firms needs to be implemented immediately. Moreover, consulting services need to be more professional and customized.
\end{abstract}

Keywords : TAA, FTA, Compensation, Korea, Trade Remedy

JEL classification Numbers : F13, F15, F16

* An earlier version of this paper was presented at Sogang IIAS Research Series on International Affairs (working paper series) in December 2012 and APEC Conference on FTA Implementation at Jeju Island on Nov. 15, 2012. The author appreciates the constructive comments made by trade delegates from APEC members.

** Professor, Graduate School of International Studies, Director, Institute of Int'l and Area Studies, Sogang University, Korea. Direct all correspondence to hury@sogang.ac.kr or Tel. 82-2-18-412-5235, Fax 82-2-705-8755. This study was supported by Special Research Grant of Sogang University (2011-10075.01). 


\section{Introduction}

One month after the Korea-Singapore FTA came into effect in 2006, the Korean Ministry of Knowledge and Economy (previously known as Ministry of Commerce, Industry and Energy) actively proposed "The Act on Trade Adjustment Assistance for Manufacturing and Related Service Industries." On April 28, 2006, the Act was finally legislated as Act No. 7947 by the National Assembly and was enforced one year after its promulgation.

Trade adjustment assistance (TAA) is a government compensatory and assistance program that aims to help reimburse domestic firms and workers for their material loss or expected loss due to the result of policies implemented toward a free trade regime. Currently, the United States is the only country that has systematically institutionalized and consistently operated the TAA program. Although programs, such as the EU's Structural Fund (ESF), Japan's System for Revitalizing Industrial Competitiveness, Mexico's Sectoral Promotion Programs (PROSEC) and Canadian, Chilean, Czech and Polish business remedy programs have been in existence, they are not considered as TAA programs. Instead, these programs are part of the industrial policies that target at strengthening the competitiveness of weak industries (or regions).

The TAA program is essential for the Korean government in order to smoothly implement the KOR-US FTA, Korea-EU FTA as well as other already concluded or prospective FTAs, such as Korea-China FTA, by facilitating internal negotiations. However, the background against which the TAA program was introduced and the details of the operation scheme remain controversial, making it difficult to reach a consensus even among policymakers and scholars in the area. Unlike the U.S. TAA, in which major resources are administered by the Department of Labor as a form of a compensatory and extended scheme for Social Security, the TAA in Korea is mainly set to be operated by the Korean Ministry of Knowledge and Economy through accommodating policies to the opinions of the business sector. As a result, the TAA program in Korea shows a strong inclination toward the industrial policy that protects and assists marginal small and medium Korean enterprises from the intensified import competition.

This raises questions regarding the main purpose of the system and its effectiveness in many ways. This paper aims at synthetically reviewing and analyzing the TAA system in Korea and then deriving the detailed policy implications. In doing so, the paper's focus centers on the following questions. First, what are the major contents and operational 
process of the Korean TAA? Second, what are the current developments and changes of the system? Third, how can we assess the performance of the Korean TAA system? Lastly, what are the policy implications that we can derive from the experiences of Korea and the U.S.? We conclude the paper with suggestions.

\section{Trade Adjustment Assistance in Korea}

The Korean government has begun to implement the TAA system in May 2007 in order to financially support firms whose sales, production and profits have decreased. It also has intended to provide workers who are completely or partially laid off or are threatened with job loss due to increased imports. The program appears to have a structure similar to the U.S. TAA system. However, with a deeper examination into the substance of the program, its major contents, particularly the purpose of the program and its consequent allocation of resources, make the Korean TAA quite different from that of the U.S..

Operation System: The TAA Committee (Chairperson: Minister of Knowledge and Economy, previously chaired by Minister of Planning and Finance prior to July 2012) was established in order to adjust policies, including the deliberation, resolution and development of TAA-related programs. The committee consists of a maximum of 15 members and each member serves a two-year term in office. The Ministry of Knowledge and Economy (MKE) and the Ministry of Employment and Labor (MEL) manage the programs for firms and workers, respectively. The Vice Minister of Knowledge and Economy chairs the TAA Administrative Committee, which consists of a maximum of 20 members serving two-year terms. The MKE leads the two teams under the administrative committee: the Adjustment Plan Evaluation Board, which is in charge of reviewing the feasibility and enforcement of the trade adjustment plan of the firms, and the Trade Adjustment Assistance Center (TAAC), which is in charge of providing detailed assistance to firms. The MKE consigned the establishment of the TAAC to the Small Business Corporation. Firms submit petitions for certification to the MKE through the TAAC, which provides assistance regarding the filing of certification petitions, assessment of firms' viability, development of adjustment plans, consultation, provision of information and technical support for the implementation of adjustment plans. Once the Korean Trade Commission evaluates the qualification of the firms and the Adjustment Plan Evaluation Board approves the adjustment plan, the ministry certifies the TAA firms. Four different types of documents were required to be filled out for the application; however, it is now 
reduced to two types by the $『 2012$ TAA Act $』$, making the process simpler and more convenient for firms. The MEL is responsible for investigating and certifying petitions for workers as well as for assisting workers through local labor offices. The worker representative or the employer can submit the TAA application form to the MEL.

Firm Eligibility : To be eligible, the firm should fall under all of the following categories: (i) a firm is severely injured (total sales or production is reduced by more than $10 \%$ during the period of more than six months), or will be severely injured; (ii) increased imports (from the parties which signed the FTA only with Korea) of articles like or directly competitive with the firm's products is the major cause of such injury in (i); and (iii) the plan for trade adjustment (hereafter, AP) of the corresponding firm should be adequate to secure the competitiveness of the firm. The Korean Trade Committee is responsible for examining the firm's compliance with conditions (i) and (ii), whereas the Adjustment Plan Evaluation Board examines the compliance with condition (iii). In 2007, the serious injury criterion was recorded at $25 \%$. However, this number has been revised to $10 \%$ by the 『2012 TAA Act』, which also provided firms with a 5\% reduction of sales or production due to increased imports in order to obtain consulting services to improve its competitiveness.

Worker Eligibility : To be eligible for the TAA, workers must fall under all of the following categories: (i) an employee who is currently laid off or has a high possibility of being laid off or currently has or will have $70 \%$ or less working hours compared to those for the past two months; (ii) an employee (including the unemployed) of a firm that falls under any of the following categories: A. worker whose firm is a TAA firm; B. worker of an upstream supplier or a downstream producer to a primary TAA firm; C. worker of a firm that has shifted its production facilities abroad due to increased imports as a result of the FTA and therefore, manufactures similar products or products in direct competition with the imported goods; D. Although the worker falls under the categories (i) and (ii), the firm did not file a petition for certification as a TAA firm or the submitted adjustment plan was not approved by the board. An upstream supplier is a firm that produces and supplies component parts directly to TAA firms, and a downstream producer performs an additional, value-added production process directly for a firm for articles that were the basis for certification, including final assembly, finishing or packaging.

Benefits for TAA Firms : Financial support is the major part of the benefits for TAA firms. The government finances the firm to purchase raw and subsidiary materials as well as to purchase or lease factory sites in order to maintain production operation. The 
government also assists firms to implement the approved adjustment plan by providing loans for business restructuring and conversion, management improvement, development of technology, facility investment and employee training. The loan has an annual interest rate of $4.75 \%$, and its amount is limited to 3 billion won for facility investment and 500 million won for operational use. The loan period is eight years for facility investment and five years for operational use. The estimated financial need for the next 10 years was estimated to be 2,463 billion won; 20 billion won of the budget had been already allocated in 2007, the first year of implementation. Moreover, the government provides information (on capital, manpower, technology, market and location) necessary for trade adjustment and consultative assistance on business management (such as finance and marketing) and technological areas (such as operation management, quality control, R\&D and certification). In the case of consultative support, the financial limit for strategic trade adjustment support is planned at 24 million won, while the financial support for partial management and technological improvement is planned at 16 million won. The estimated amount of the consultation-related budget for the next 10 years was 107 billion won, of which 760 million won was allocated in the 2007 fiscal year. Investment support is another method that a Corporate Restructuring Company (CRC) can use in order to invest in a TAA firm by forming a corporate restructuring association to finance up to $50 \%$ of the association investment. Seventy billion won is expected to be allocated in the next 10 years.

Benefits for TAA Workers : The MEL provides TAA workers with information on industry trends, labor demand, vocational education and new business establishment. It also provides consultative assistance on reemployment and job transfers. Financial support for job transfers, employment, reemployment and extended training allowance (TRA) is also provided under the supervision of the MEL. However, these types of supports are applied not exclusively to trade-displaced workers but to all the unemployed. Specifically, TAA certified workers do not receive any special or differential treatment compared to other job separators.

Timeframe : The MKE should inform the firm of the ministry's determination within two months after receiving the application (The Trade Commission: one month, AP Evaluation Board: one month) and the MEL within one month. When the time period for trade damage passes two years, the firm will be unable to apply for the TAA certification. The implementation period of a trade adjustment plan is within five years upon certification. When the firm wishes to receive financial and consultation support, the firm should submit an application to the MKE together with the detailed list of the required capital within three years after being certified as a TAA firm. 
Table 1.

Performance of TAA for Firms in Korea

(unit: mil. Korean Won)

\begin{tabular}{|c|c|c|c|c|c|c|c|}
\hline \multirow[b]{2}{*}{ \# } & \multirow[b]{2}{*}{ Item } & \multirow[b]{2}{*}{ Origin } & \multirow[b]{2}{*}{$\begin{array}{l}2111 \\
\text { Sales }\end{array}$} & \multirow{2}{*}{$\begin{array}{c}\text { Reduced } \\
\text { amount of } \\
\text { sales } \\
\text { (6 months) }\end{array}$} & \multirow[b]{2}{*}{$\begin{array}{c}\text { Date of } \\
\text { certification }\end{array}$} & \multicolumn{2}{|c|}{ Assistance } \\
\hline & & & & & & Financing & Consulting \\
\hline 1 & $\begin{array}{l}\text { Wild grape } \\
\text { wine }\end{array}$ & Chile & 1,012 & 399 & ‘08.10.31 & 450 & 16 \\
\hline 2 & $\begin{array}{l}\text { Packaged } \\
\text { pork }\end{array}$ & Chile & 5,676 & 200 & ‘08.12.15 & 100 & 16 \\
\hline 3 & $\begin{array}{l}\text { Packaged } \\
\text { pork }\end{array}$ & Chile & 9,865 & 1,259 & '09.06.04 & 300 & - \\
\hline 4 & $\begin{array}{l}\text { Salted } \\
\text { mackerel }\end{array}$ & $\begin{array}{l}\text { Norway } \\
\text { (EFTA) }\end{array}$ & 13,000 & 1,197 & '09.11.04 & 300 & 16 \\
\hline 5 & Golf wear & $\begin{array}{l}\text { Vietnam } \\
\text { (ASEAN) }\end{array}$ & 9,090 & 1,122 & '10,12,01 & 1,000 & - \\
\hline 6 & $\begin{array}{l}\text { Wild berry } \\
\text { wine }\end{array}$ & Chile & 1,197 & 363 & '10.12.01 & 100 & 16 \\
\hline 7 & Carcass pork & Germany etc. (EU) & 10,977 & 1,745 & ‘12.8.28 & 200 & - \\
\hline 8 & $\begin{array}{l}\text { Functional } \\
\text { shampoo }\end{array}$ & France etc. (EU) & 548 & 300 & '12.10.4 & \multirow{3}{*}{\multicolumn{2}{|c|}{ Under review }} \\
\hline 9 & T shirts & $\begin{array}{l}\text { Vietnam etc. } \\
\text { (ASEAN) }\end{array}$ & 12,561 & 1,197 & '12.10.4 & & \\
\hline 10 & $\begin{array}{l}\text { Paint } \\
\text { hardener }\end{array}$ & Germany etc. (EU) & 589 & 739 & '12.10.4 & & \\
\hline Tot. & & & & & & 2450 & 64 \\
\hline
\end{tabular}

Small Firm Corporation (2012)

\section{Assessment of TAA Operation in Korea and Policy Implications}

$<$ Table-1 $>$ shows the performance of TAA operation in Korea from its launch to the present. As we can see in the table, only seven firms are designated to be certified recipients of the TAA program. The total amount of financial assistance and consulting service are 2.45 billion won and 64 million won, respectively. The assessment of the program based on its performance so far can be summarized as below. 


\section{Distorted Allocation of Limited Resources}

The Korean TAA system can be characterized by an industrial policy, which reinforces the existing assistance targeted at marginal firms. According to the law, the Korean government provides financial support for trade-related injured firms in order to stabilize short-term management, convert the business and improve the firm's competitiveness as well as to provide consultative support on management, technology, etc. Financial support for business conversion and competitiveness improvement include technology development, investment in equipment, guarantee of human resources training. The problem is that the support for the firm to exit the industry, which is essential for TAA, is excluded in the service. Clearly, the Korean TAA contrasts with the U.S. TAA in that the U.S. confines its fundamental assistance (to the firms) to the provision of consulting services for management restructuring and technological development, while banning any kind of support for improvement in production equipment, introduction of new machines and financial loans after 1986. The U.S. allocates approximately $1 \%$ of the total $\$ 1$ billion budget to firms, $9 \%$ to farmers and the remaining $90 \%$ to workers. The budget of a single U.S. Trade Adjustment Assistance Center (TAAC) has been approximately 1 million USD per year; each center is responsible for one firm each month. Each firm receives government financial support of less than approximately $\$ 55,000$. In contrast, according to the MKE, the Korean government has planned to allocate $92 \%$ of the budget (2,845 billion won) to firms and less than $8 \%$ to workers from 2007 - 2016. However, due to the inconvenience in the application process along with the limited information about the program, only seven firms are certified for the TAA program. This empirical result is quite disappointing in that the Korean government advertised the TAA program to the public quite often as an effective trade defense system against trade liberalization movement. Overall, the TAA performance is a failure and the direction of the assistance has wandered off the path.

\section{Limited Scope of the TAA System}

In the United States, if a causal relationship is found such that increased imports of similar or directly competitive products greatly contribute to the decrease in production of certain firms or worker layoffs, then they are the targets of TAA, regardless of the types of trade liberalization negotiations, i.e., bilateral, trilateral, regional or multilateral. If there is a shift in production to other countries, the firm is also eligible for the TAA incentive package. However, Korea has a different scheme and indeed, Korea can face an equity 
debate among the firms and workers in various industries over the relevance of the scope of the TAA program. For example, the injuries from import competition with the U.S. can be partially covered by the government while those from Japan cannot. The case for removing trade barriers through multilateral trade negotiations is not included in the program either. Favoring an injured group due to FTA implementation could be positive in the short term because it amicably promotes FTA implementation. However, in the mid- and long-term, it is desirable to reduce the size of the neglected injured group by expanding the support to all firms and workers injured by free trade. In the U.S., the agricultural and fishery sectors are incorporated into TAA. With the 2009 TAA Act』, the U.S. included not only services but also public sector workers.1 In Korea, TAA focuses on the manufacturing industry and services, while the agricultural sector is fundamentally excluded from TAA coverage. It seems that the related assistance programs for the agricultural sector should be incorporated into a consolidated TAA system in the mid- and long-term. It is advisable to incorporate all industries into an integrated TAA program and facilitate an internal negotiation process among the interested groups and the government.

\section{Unified Process of Certification}

In the U.S., the U.S. International Trade Commission (USITC) has been in charge of certification. The Division of Trade Adjustment Assistance (DTAA), under the Department of Labor, administers individual certification; the Economic Development Administration (EDA), under the Department of Commerce, administers firm certification; and the USITC administers farmer certification. Thus, in addition to the unorganized data collection and control, the administration could be somewhat unprofessional. In the case of Korea, it would be advisable to unify the certification of injured workers or firms under a specialized government agent, such as the Korean Trade Commission (KTC). In Korea, the MEL administers TAA certification for workers, whereas KTC and the Adjustment Plan Evaluation Board administer the TAA certification processes for firms. In the near future, the certification processes need to be unified through KTC, which has accumulated expertise in assessing the existence of trade-related injuries.

\section{Strengthening the Monitoring System}

Many academic papers and reports in the U.S. have pointed out the problems of collecting and sharing the U.S. TAA-related data. These problems could obstruct the organized and appropriate assessment of the system itself and severely waste resources. 
Therefore, the collection and control of the related data should be guaranteed before the full-fledged operation of the TAA system. It is necessary to construct a data interchange system in order to ensure the collection of data among the related institutions. GAO (2006) submitted a report to the U.S. Congress calling for a systematic collection of up-to-date data to correct the current controlling, storing and distribution problems. Since the criteria of the eligibility for certification has been relieved beginning from July 18, 2012, the number of applicant firms has rapidly been increasing. Even though the MKE in Korea issues the enforcement ordinance, and the MEL manages the TAA statistics, it should be more concretely specified and system oriented with harmonized efforts of all related government agencies.

\section{Relevance of the Budget for Trade Adjustment Assistance}

The TAA system is a political device set its sight on easing the opposition or winning the silence of the injured interest group in the process of the expansion of trade. Thus, providing sufficient compensation for trade-related damage or seeking industrial restructuring as an industry policy could rather delay the restructuring by undermining the benefits of free trade. TAA is basically a social cost going along with free trade; hence, the compensation must be reasonable, not sufficient. Reasonable compensation means the level where internal negotiations could be successfully achieved. The government (particularly the FTA Promotion and Policy Adjustment Authority under the Ministry of Planning and Economy) and interest groups (such as industries and unions) should negotiate in order to determine the amount of compensation, given the government's limited financial capacity. If we compare the U.S. budget, trade volume and the actual TAA expenditure, we see that the U.S. TAA system provides compensation at the "minimum level."2 In the case of Korea, a survey of the injured firms and/or estimate of the decrease in sales by CGE or partial equilibrium analysis are used to identify the appropriate amount of TAA expenditure. It can easily overestimate the amount of loss due to the nature of the survey and also lack scientific accuracy in its method.

\section{TAA: Is it a Facilitating Device for FTA Implementation?}

Greg Mastel and Howard Rosen (2012) best enunciated the nature of TAA when they wrote, 
"The marriage between TAA and opening U.S. markets to trade has allowed the United States to pursue a mostly free trade policy throughout the post-WWII era. Breaking the linkage threatens the current FTAs and all future trade agreements."

Public opinion surveys in the U.S. find that Americans are willing to pursue trade liberalization if the government assists workers, farmers, firms and communities, which are adversely affected by liberalization (Rosen, 2008). The Peterson Institute for International Economics estimates that international trade with all countries benefits the U.S. economy by more than $\$ 1$ trillion a year. The $\$ 1$ billion TAA budget is a tiny investment in addressing the needs of displaced workers, which will continue to yield outsized returns.

However, the Korean TAA system can be characterized as an industrial policy aimed at strengthening the manufacturing and related industries, expanding support to small and medium firms and minimizing the role of the MEL. As the Korean government adopts an experimental support scheme for marginal firms as the essential part of TAA, the government has imposed a burden on itself of proving the efficiency of operating the system. Based on the TAA experience in Korea for the past five years, we conclude that the newly introduced Korean system failed to accomplish the objectives of the program it had planned. It also failed to be an effective means for internal negotiations. All the efforts to retain marginal firms in comparative disadvantage turned out to be a big failure. This poor performance will threaten the system's own existence in the near future. Even if the TAA system continues to exist, it will inevitably be converted into a worker-centered program instead of a firm-oriented industrial policy. As argued by Spence (2011), it could be a strategy mistake to protect people by protecting their jobs. We need to protect people by providing income support during periods of unemployment, effective retraining, and subsidized access to health, education, and other basic services (Spence, 2011).

It is fair to propose that curtailing or abolishing the financial assistance program for marginal firms needs to be implemented immediately. It could only undermine the benefits of trade liberalization. Moreover, consulting services need to be more professional and customized. Some studies reveal firms' complaints against the quality of consulting services arranged by the government. In the future, the Korean government should place more and more weight on its assistance to trade-related workers, who are the ultimate victims of import liberalization, rather than on the firms. 


\section{$<$ Endnotes $>$}

1. For details of the U.S. 『2009 TAA Act』, see Hombeck (2011) and Topoleski (2010). For the community program, particularly Community College and Career Training (CCCT) Grant Program, see ETA (2012).

2. Key developments in the U.S. TAA programs in 2011 were the lapse on Feb.2, 2011, of certain expansions made to TAA in 2009, and the restoration of these expansions on Oct.21, 2012. For the current performance of U.S. TAA programs, see USITC (2012). 


\section{References}

ETA (2012), TAACCCT: Program Summary, USDOL

GAO (2006), "Labor Should Take Action to Ensure Performance Data are Complete, Accurate, and Accessible, "GAO-06-496.

Heo, Yoon (2007), "Trade Adjustment Assistance in Korea: Theory and Practice," pp. 133-150, The Korean Economy in the Era of Globalization, ed. by MoonJoong Tcha, KDI Press

Hornbeck, J.F.(2011), Trade Adjustment Assistance for Firms: Economic, Program, and policy Issues, CRS Report, RS20210

Mastel, G. and H. Rosen (2012), TAA Reauthorization; necessary and appropriate, Congress Blog, The Hill

Rosen, H.F. (2008), Assisting Workers, Firms, Farmers and Fishermen and Communities Adversely Affected by Changes in International Trade and Investment: The US Experience, Peterson Institute for International Economics

Spence, Michael. 2011. The Next Convergence: The Future of Economic Growth in a Multispeed World, Farrar, Straus and Giroux: New York

Topoleski, J.(2010), Trade Adjustment Assistance for Workers(TAA) and Reemployment Trade Adjustment Assitance(RTAA), CRS REport, RS22718

USITC (2012), The Year In Trade 2011: Operation of the Trade Agreements Program, $63^{\text {rd }}$ Report, USITC Publication 4336

\section{Web-site}

http://www.taa.go.kr (Korea, TAA)

http://www.doleta.gov/tradeact (US, Worker TAA)

http://www.fas.usda.gov/itp/taa/ (US, Farmers and Fishermen TAA)

http://www.taacenters.org/ (US, Firm TAA)

http://doleta.gov/taaccct/ (US, Community TAA) 